\title{
Caracterização da cadeia produtiva de madeira para movelaria e carpintaria naval em Óbidos, Pará
}

O setor madeireiro na Amazônia contribui expressivamente para a economia local, regional e nacional, assim como para a geração de empregos e desenvolvimento. No entanto, enfrenta entraves como a falta de políticas e ações voltadas para a consolidação de uma base florestal que venha atender as demandas de quem depende da madeira como matéria prima em pequenos municípios da Amazônia, como Óbidos, no Estado do Pará. Neste sentido, este trabalho procurou identificar por meio de estudo perceptivo, informações sobre a produção florestal para fins de construção de móveis e pequenas embarcações em Óbidos, destacando sua importância socioeconômica e os principais gargalos da cadeia produtiva da madeira. Foi aplicado um questionário semiestruturado, através de entrevistas com os atores chave envolvidos no processo, sendo eles empreendedores, representantes institucionais e empresários, utilizando o método não probabilístico bolade-neve e a lei de acesso à informação. Os resultados obtidos demonstram que a crescente escassez de matéria prima por meios legais incentiva as práticas predatórias de exploração da madeira, o que ocasiona a degradação da floresta e dificulta o fluxo da cadeia produtiva da madeira na cidade e região, atrelado a isso, a falta de políticas públicas voltadas para realidade local, a falta de assistência técnica e a burocratização no processo de regularização impedem avanços no setor.

Palavras-chave: Cadeia produtiva; Madeira; Movelaria; Carpintaria naval; Óbidos.

\section{Characterization of the wood productive chain for furniture and naval carpentry in Óbidos, Pará}

\begin{abstract}
The timber extraction sector in the Amazon greatly contributes to the local, regional and national economy, as well as to the generation of jobs and economic growth. However, the sector faces difficulties as the lack of policies and actions towards the consolidation of a forestal base that can supply the demands from who depends on timber for raw material in the smaller municipalities of the Amazon, like Óbidos-PA. In this sense, this study looks to identify by means of perceptual study, information about the local forestal production towards furniture construction and small naval vessels in Óbidos, highlighting the socioeconomic importance of these practices and the main bottlenecks in the productive chain of timber. A semi-structured questionnaire has been applied, through interviews with key players involved in the business, like entrepreneurs, institutions representatives and business owners, using a non-probabilistic method known as snowball and the law of information access. The obtained results shown that the rising scarcity of raw materials obtainable from legal means encourages predatory practices of timber extraction, which causes forest degradation and hinders the timber supply chain in the city and region, as well as the lack of policies that take into account the local reality, the lack of technical assistance and the bureaucracy in the regulation haltes advancement in the sector.
\end{abstract}

Keywords: Production chain; Wood; Furniture; Naval carpentry; Óbidos.

Topic: Desenvolvimento, Sustentabilidade e Meio Ambiente

Reviewed anonymously in the process of blind peer
Received: 09/03/2021

Approved: 21/05/2021
Izis Aniê de Paiva Câncio (D)

Universidade Federal do Amazonas, Brasil http://lattes.cnpq.br/3603211388424421

http://orcid.org/0000-0001-5774-1238

izispaiva.10@hotmail.com

\section{Rogério Fonseca (iD)}

Universidade Federal do Amazonas, Brasil

http://lattes.cnpq.br/9737977542201724

http://orcid.org/0000-0003-1941-3924

rogeriofonseca@ufam.edu.br

\section{Peterson Silva de Sousa}

Universidade Federal do Oeste do Pará, Brasi

http://lattes.cnpq.br/3726505759262591

http://orcid.org/0000-0003-2203-2452

petersonflorestal@gmail.com
David Franklin da Silva Guimarães

Universidade Federal do Amazonas, Brasil

http://lattes.cnpq.br/5505567867578844

http://orcid.org/0000-0002-4569-6000

davidguimaraes@ufam.edu.br
Referencing this:

CÂNCIO, I. A. P.; FONSECA, R.; SOUSA, P. S.; GUIMARÃES, D. F. S. Caracterização da cadeia produtiva de madeira para movelaria e carpintaria naval em Óbidos, Pará. Nature and Conservation, v.14, n.2, p.84-99, 2021. DOI: http://doi.org/10.6008/CBPC23182881.2021.002.0009 


\section{INTRODUÇÃO}

De acordo com May et al. (2005), o setor madeireiro na Amazônia tem grande importância para o desenvolvimento da economia no país, gerando emprego e cumprindo um relevante papel social, porém é importante ressaltar que a Amazônia não pode perecer por falta de uma política clara e responsável que valorize a região, sendo necessário desenvolver iniciativas que combatam a ação predatória e que valorize a população local.

A atividade florestal está ligada a vários segmentos que atendem um conjunto de atividades específicas, porém, os meios para o progresso do setor como um todo devem estar relacionados a uma base florestal bem articulada, e para isso, Moreira (2017) afirma que "considera-se fundamental reunir informações sobre a sustentabilidade e importância do setor florestal, objetivando apoiar seu crescimento e de toda a cadeia produtiva da madeira".

Para se fazer uso dos recursos florestais é necessário estar em conformidade com as dimensões econômica, ambiental e social da sustentabilidade, descritas em documentos oficiais de instituições nacionais como o Instituto Brasileiro do Meio Ambiente e dos Recursos Naturais Renováveis (IBAMA), Serviço Florestal Brasileiro (SFB) e estaduais, como o IDEFLOR (Instituto de Desenvolvimento Florestal e da Biodiversidade do Estado do Pará), porém a prática não contempla esses princípios, apresentando falhas que dificultam a consolidação das atividades do setor.

Junto à mineração e à pecuária, a atividade madeireira é uma das atividades econômicas mais importantes da Amazônia (PEREIRA et al., 2010), e conforme Cassilha et al. (2003), mesmo sendo possível substituir por outros materiais em algumas aplicações, a madeira continua sendo a principal matéria prima na produção de móveis. Em Óbidos, no oeste do Pará, a construção de móveis e embarcações formam a base da economia da cidade, atendendo o mercado local, através de movelarias e tilheiros de carpintaria naval, porém, poucas são licenciadas para o funcionamento, e quando regularizadas, encontram mais um entrave no processo que é a falta da oferta de matéria prima legal.

Desta forma, este trabalho teve como objetivo identificar, por meio de estudo perceptivo, informações sobre a produção florestal para fins de construção de móveis e pequenas embarcações no município de Óbidos, no Pará, destacando sua importância socioeconômica e os principais entraves na cadeia produtiva da madeira.

\section{REVISÃO TEÓRICA}

\section{Regularização dos empreendimentos}

Em primeiro lugar, é importante saber que o Licenciamento Ambiental é uma obrigação legal para a instalação de qualquer empreendimento ou atividade causadora de impacto ambiental, instituído através da Lei Federal 6.938/81, pela resolução no 237 do CONAMA (BRASIL, 1997). O descumprimento da norma pode acarretar em sanções, notificações e multas.

Movelaria e carpintaria naval estão sujeitas à legislação ambiental e precisam regularizar suas 
atividades, porém, este caminho é oneroso e precisa de apoio técnico em todas as etapas. Apesar das movelarias e tilheiros de carpintaria naval serem atividades com alto potencial para a economia do município de Óbidos, atualmente notam-se falhas na articulação entre órgãos de gestão e empreendedores, o que reflete na baixa quantidade de empreendimentos regularizados.

\section{Legalização da madeira}

A matéria prima utilizada em Óbidos é obtida através de madeireiros localizados em diversas áreas ao redor do município, sendo privadas ou não, de modo convencional. Essa prática vem sendo feita há anos, o que compromete cada vez mais a disponibilidade dos recursos e torna a atividade instável e vulnerável, se tornando alvo dos órgãos de fiscalização.

Como citado por Zenid et al. (2009), a legislação brasileira permite a extração de madeira da floresta de duas formas: a partir de manejo florestal ou da conversão das áreas de florestas para agricultura e pecuária (desmatamento); este desmatamento somente pode ocorrer mediante autorização de um órgão estadual ou do IBAMA, sendo vetado este recurso somente para a extração de madeira.

A madeira extraída sem licença exigida ou em desacordo com uma licença ou lei de exploração é tida como ilegal. A exploração ilegal de madeira e o desmatamento estão diretamente associados. O lucro da venda de madeira ilegal geralmente financia o desmatamento, a ocupação desordenada e a queimada para a transformação de extensas áreas em pastos ou plantações agrícolas, a despeito dos interesses das pessoas que dependem da floresta (MILLER, 2006).

A madeira legal é aquela que cumpre todos os requisitos previstos na lei quanto à documentação (emitida pelo órgão ambiental federal ou estadual) e pode vir tanto de manejo florestal como de desmatamento, desde que autorizado pelos órgãos ambientais (BRAGA et al., 2011).

\section{Sistema de controle de produtos florestais}

A Secretaria Estadual do Meio Ambiente - SEMAS/PA, possui um sistema próprio de controle e monitoramento dos produtos de origem florestal, denominado SISFLORA - Sistema de Comercialização e Transporte dos Produtos Florestais do Estado do Pará, integrado ao CEPROF - Cadastro de Exploradores e Consumidores de Produtos Florestais do Estado do Pará.

Segundo a Instrução Normativa no 01 de 05 de Maio de 2017,

O CEPROF é o banco de dados de inscrição obrigatória às pessoas físicas e jurídicas responsáveis por empreendimentos que visem o exercício, no âmbito do Estado do Pará, das atividades de extração, coleta, beneficiamento, transformação, industrialização, comercialização, armazenamento ou consumo de produtos, subprodutos ou matéria prima de qualquer formação florestal, inclusive de plantios dentro da área de Reserva Legal, plantios de espécies nativas e aquelas destinadas à fonte de energia.

A inscrição no CEPROF é feita no âmbito estadual, através da Secretaria Estadual de Meio Ambiente - SEMAS/PA, mediada por um profissional da área, que poderá ter acesso ao SISFLORA com um cadastro próprio. A inscrição no CEPROF tem exigências documentais específicas, que tornam o processo oneroso e parcialmente inviável para um pequeno empreendedor. Um exemplo disso, é a taxa de inscrição que tem 
valor único para todas as atividades, independente do porte ou potencial poluidor, fixada em $\mathrm{R} \$ 692,34$ no ano de 2019 (Portaria SEFA, 2018), além de uma taxa de solicitação da inscrição que é cobrada além da taxa de inscrição em si.

Somente após a ativação do CEPROF que o estabelecimento poderá comprar a madeira que será consumida na empresa, ficando dessa forma apto ambientalmente para funcionar. O cadastro no sistema SISFLORA/CEPROF possui prazo de validade e deve ser renovado antes do vencimento.

\section{O papel da gestão pública}

Uma das abordagens para evitar e controlar as crises ambientais deve ser originada na gestão ambiental pública, notadamente na atuação integrada dos seus instrumentos: o licenciamento, o monitoramento e a fiscalização (SOUSA, 2013). Uma vez que o papel do órgão de comando e controle se concentra em apenas uma dessas vertentes, o sistema deixa de ser sinérgico e entra em colapso.

Neste sentido, gestão ambiental, é definida no trabalho de Quintas (2006), como o "processo de mediação de interesses e conflitos (potenciais ou explícitos) entre atores sociais que agem sobre os meios físico-natural e construído, objetivando garantir o direito ao meio ambiente ecologicamente equilibrado, conforme determina a Constituição Federal”. Diante disso, entende-se que o Poder Público é o mediador principal deste processo, uma vez que é possuidor dos instrumentos legais pertinentes ao ordenamento e controle das ações.

A política florestal exige comprometimento com todas as etapas inerentes ao processo. Para Coimbra (2004), a administração precisa ser participativa, integrada e contínua, e isso deve ser feito por meio da ação conjugada do poder público e da sociedade organizada em seus vários segmentos. Essa relação deve ser pautada no diálogo e respeito a cada realidade, adequando-se as especificidades encontradas, sempre buscando alternativas para mediar e encontrar soluções.

\section{Unidades de Conservação como alternativa}

Vários estudos evidenciam a importância das Unidades de Conservação - UCs, principalmente na Amazônia, para o desenvolvimento regional de forma sustentável. O Sistema Nacional de Unidades de Conservação da Natureza (SNUC), instituído em 2000, estabelece como um de seus objetivos "promover o desenvolvimento sustentável a partir dos recursos naturais" (Idem, Art. 4‥ IV). Dessa forma, Teixeira (2005) diz que a ideia de gestão de áreas protegidas perpassa pela promoção do desenvolvimento sustentável.

As Unidades de Conservação são regidas pela Lei 9.985/2000, que criou o (SNUC), e são divididas em dois grupos: proteção integral e uso sustentável, sendo que este último garante às populações tradicionais o uso dos recursos naturais de forma racional e ainda propiciam às comunidades do entorno o desenvolvimento de atividades econômicas sustentáveis.

\section{MATERIAIS E MÉTODOS}

O local de estudo foi Óbidos (Figura 1), uma cidade no oeste do Estado do Pará, localizada na região 
da Calha Norte, à margem esquerda do Rio Amazonas, na sua parte mais estreita e profunda. Limita-se com Suriname e com os municípios de Almerim, Alenquer, Santarém, Juruti e Oriximiná. O município (Figura 1) se estende por $28.021,3 \mathrm{~km}^{2}$ e conta com 52.137 habitantes (IBGE, 2019).

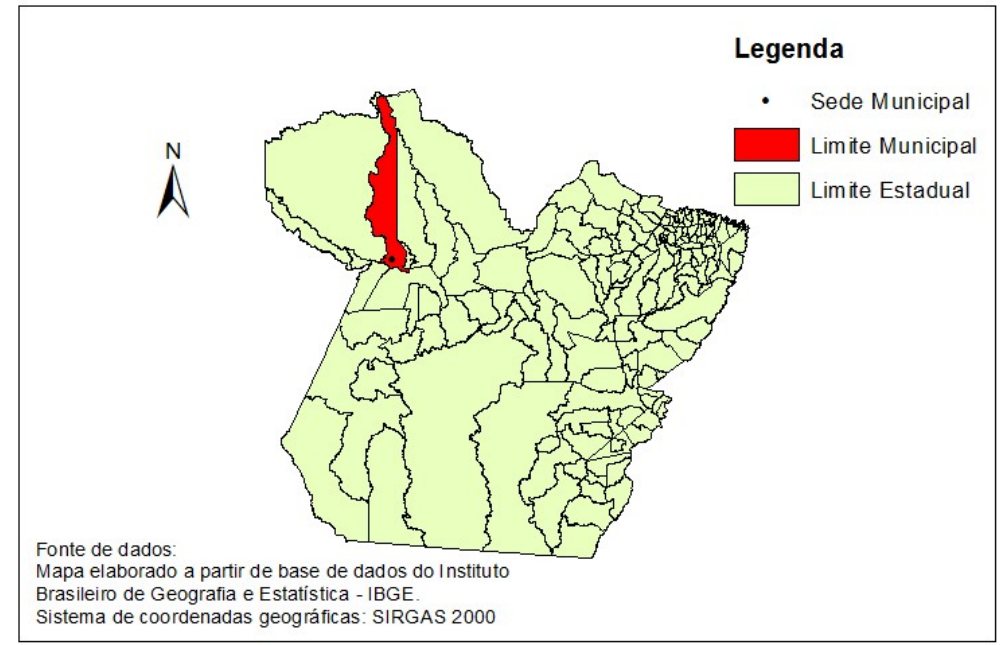

Figura 1: Mapa de localização do município de Óbidos.

Adotou-se como metodologia para acessar as informações sobre a cadeia produtiva da madeira na cidade de Óbidos, a abordagem em bola-de-neve ("snow ball") (PATTON, 2001). Essa técnica é uma forma de amostra não probabilística utilizada em pesquisas sociais onde os participantes iniciais de um estudo indicam novos participantes e assim sucessivamente, como uma espécie de rede, até que seja alcançado o objetivo proposto, que é quando os novos entrevistados passam a repetir os informes já dados em entrevistas anteriores, sem acrescentar novas informações relevantes à pesquisa (WHA, 1994).

Os dados foram coletados no período de 01 a 05 de Novembro de 2019, onde se aplicou questionários semiestruturados aos atores sociais do setor, através de visitas feitas em cada estabelecimento, com entrevistas que tiveram duração média de 30 minutos por pessoa. Além dos moveleiros e carpinteiros, também fez parte da metodologia o proprietário da única serraria legalizada na cidade, o Sr A. A., que se prontificou a prestar todas as informações necessárias para a pesquisa.

Os levantamentos de informações institucionais foram obtidos de acordo com a Lei no 12.527, de 18 de novembro de 2011 (Brasil, 2011), que garante o acesso a informações de órgãos públicos e entidades controladas direta ou indiretamente pela União, Estados, Distrito Federal e Municípios. O órgão municipal entrevistado foi a Secretaria Municipal de Meio Ambiente - SEMA, na pessoa do seu então secretário, o Sr. E. A., que respondeu integralmente ao questionário.

Além desses entrevistados, também colaborou com a pesquisa o Engenheiro Florestal P. S., de Santarém, Pará, ex servidor da SEMA de Óbidos, onde foi responsável por licenciar alguns empreendimentos no município, e devido a isso, tem conhecimento sobre a realidade local e se dispôs a compartilhar importantes informações para o estudo, através de um questionário e disponibilização de alguns dados estatísticos enviados por meio eletrônico.

Num universo de $20(\mathrm{n})$, a população amostrada foi de 13 entrevistados. Desse total, 10 foram empreendedores do setor, sendo 6 moveleiros e 4 carpinteiros, na faixa etária entre 39 e 64 anos, todos do 
sexo masculino e residentes no município de Óbidos, com seus respectivos empreendimentos em terreno próprio, também na cidade.

Os principais resultados obtidos serão apresentados seguindo os pontos mais relevantes abordados em questionários, onde foi possível fazer o diagnóstico do cenário atual.

\section{RESULTADOS E DISCUSSÃO}

\section{A percepção dos pequenos empreendedores}

Foram abordados assuntos pertinentes ao funcionamento dos empreendimentos, demonstrados na tabela 1.

Tabela 1: Dados referentes à caracterização do funcionamento dos empreendimentos amostrados na entrevista.

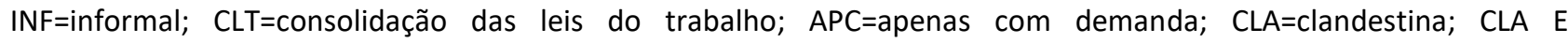

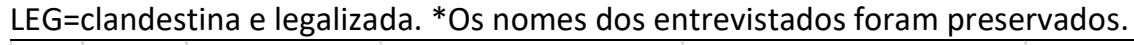

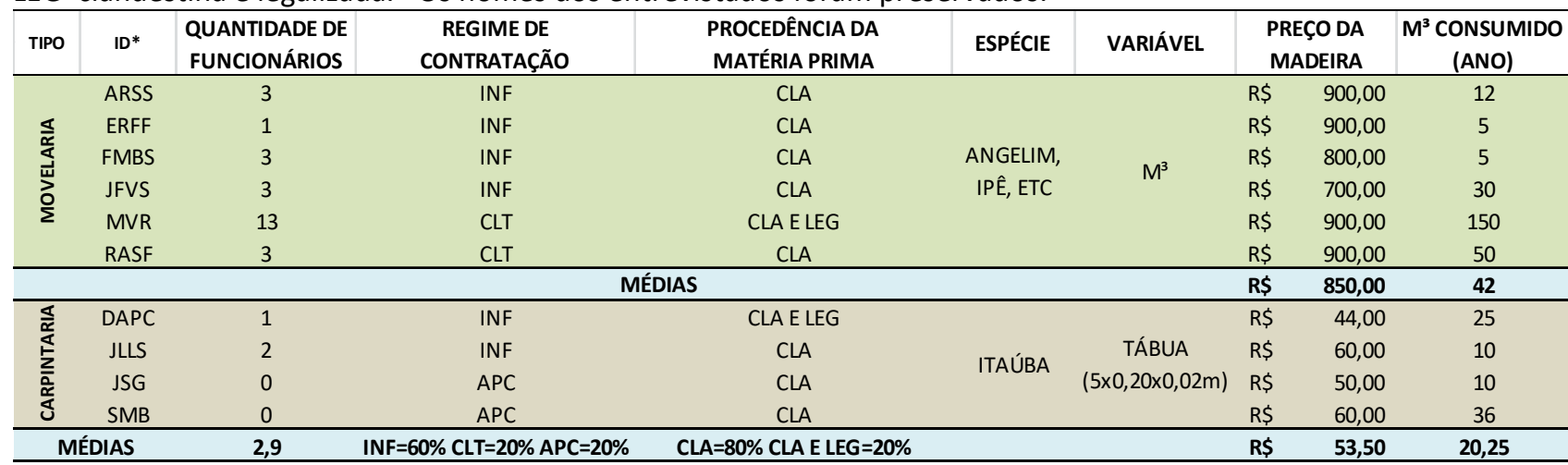

Durante a visita, notou-se que a maioria dos estabelecimentos estava com baixa atividade, sem material para trabalho e com pouco ou nenhum funcionário. No decorrer da entrevista, foram identificadas as razões para esse cenário. O questionário sobre a percepção dos empreendedores foi estruturado conforme os tópicos a seguir.

\section{Organização social}

Dentre os moveleiros e carpinteiros, todos afirmaram que no passado fizeram parte da Associação dos Moveleiros, porém, atualmente, não participam de nenhuma entidade, pois a Associação encontra-se inativa. Diante disso, faz-se necessário um meio de organização da classe, para ter representatividade na busca por melhorias para o setor.

Um modelo de organização social nesse setor é a Cooperativa Mista da FLONA Tapajós COOMFLONA, de Santarém, PA. Criada em 2005, com 24 cooperados, também surgiu da vontade coletiva dos moradores tradicionais extrativistas em melhorar sua condição social, ambiental e econômica e atualmente é composta por 203 cooperados, gerando benefícios sociais para 23 comunidades (RODRIGUES, 2019). A partir de 2001 fomentou-se a Implantação de um Plano Piloto de Manejo Florestal Comunitário na FLONA Tapajós, que atende à demanda local gerando renda e desenvolvimento sustentável.

A cooperativa se torna um modelo viável para essa classe de trabalhadores por se tratar de uma 
forma de associação entre indivíduos que tem como objetivo uma atividade comum, de forma a valorizar os produtos comercializados e gerar benefícios iguais a todos os membros.

\section{O Papel do município em relação ao setor}

Em relação às ações que os órgãos ambientais vêm desenvolvendo, a resposta de todos os entrevistados foi 'nada'. F.M.B.S. relata que todas as reuniões sempre acabam em conversa perdida e indignação dos trabalhadores, por não haver nenhuma garantia de melhorias.

Entre as principais ações realizadas pela entidade SEMA, eles citam: fiscalização, notificação, cobranças e aplicação de multas. Segundo o Sr S.M.B., a única visita do órgão ambiental no seu empreendimento foi para notifica-lo por uma denúncia de que ele havia comprado 70 tábuas ilegalmente.

O Sr J.F.V.S. fala sobre a cobrança da SEMMA pela regularização da sua atividade: 'Eu disse que não ia fazer documentação nenhuma porque não sabia por onde começar, e que se eles quisessem fechar meus portões podiam vim'.

Isso deixa evidente a falha dos órgãos competentes quanto à orientação, pois ainda segundo ele, teve um tempo que eles tentaram se organizar, mas não sabiam como e nem o que fazer e com isso desanimaram. Seu E.R.F.F. relata que eles são cobrados como se fossem os grandes empresários da região Sul, só que eles não trabalham para exportar, e acrescenta: 'Eles só querem cobrar nossos deveres, mas não dão nossos direitos'.

O carpinteiro S.M.B. afirma que eles não se negam a se regularizar, mas que a realidade atual dificulta, pois é muita burocracia, muito gasto e pouco retorno.

\section{Perspectiva sobre o futuro do setor moveleiro/carpinteiro no município}

A maioria dos entrevistados (90\%) afirmou que acredita que a atividade ainda seja promissora, mas que dependia de fatores como: interesse do prefeito, diminuição da burocracia, incentivos certos, profissionais compromissados e madeira legal para comprar.

O carpinteiro Sr J.S.G. diz que a crise que se encontram não é por falta de madeira, mas por falta de políticas públicas voltadas para o setor no município e completa sobre a importância da atividade: 'Os rios não secam, peixes serão sempre alimentos e pescadores sempre precisarão de embarcação'.

O Sr. F.M.B.S. revela que se não tivesse uma fonte de renda extra, estaria passando fome, pois o rendimento da atividade moveleira hoje em dia só cobre os gastos com a manutenção do empreendimento. O moveleiro E.R.F.F. disse não acreditar mais que a atividade ainda tenha futuro na cidade e que inclusive já está em processo de fechamento do seu estabelecimento, preferindo buscar outras alternativas: 'Tem procura, porque a qualidade do serviço é boa, mas não tem material para fazer. Aí a gente fica sem saída. A gente já deu muito murro em ponta de faca, trabalha parece bandido'.

Apesar de existir demanda pelos produtos comercializados nessas atividades, a dificuldade sempre esbarra na questão da matéria prima, uma vez que por ser obtida por meio ilegal, se torna um perigo constante para os trabalhadores se submeterem a compra, além dos gastos com o material, logística e 
transporte. No final desse ciclo, os empreendedores acabam perdendo clientes, e sem um retorno financeiro necessário para manter seus negócios, a opção é desistir da atividade.

\section{Os principais gargalos da deficiência do fornecimento de madeira legal no município}

O assunto mais pertinente nas respostas foi em relação à burocratização imposta pelos órgãos de comando e controle. O moveleiro E.R.F.F. diz que falta uma lei municipal que ampare o Plano de Manejo na cidade para atender a demanda dos trabalhadores locais, pois todo Plano de Manejo que existe é para atender demanda de fora. F.M.B.S. acrescenta dizendo que o Estado não dá autonomia para o município legalizar de forma integral, pois o CEPROF é estadual, e eles dependem dele para comprar madeira no município.

Seu D.A.P.C. fala sobre as áreas que estão tomadas por assentamentos, e que, portanto, não podem ser exploradas, que poderia haver um meio de buscar parcerias locais para criar alternativas, pois todo projeto que surge é para exportação, não restando nada para eles.

A falta de oferta de madeira legal foi uma questão citada por todos os entrevistados, que colocam como um dos principais fatores limitantes para a regularização de suas atividades, pois dizem que não vale a pena gastar com regularização porque não tem de onde comprar a matéria prima, como cita J.L.L.S.: 'A gente até quer fazer tudo dentro da lei, estamos dispostos, mas e depois, de onde vamos comprar madeira legal?'

O moveleiro A.R.S.S. destaca que tem serraria legal na cidade, mas que a empresa tem contrato com um projeto de exportação, e por esse motivo tem madeira, mas não podem vender para os moveleiros da cidade. Este cenário enfatiza como a política pública direcionada ao desenvolvimento local é fundamental para a viabilidade da atividade.

Como as políticas públicas são insuficientes devido a falhas de governança em todas as instâncias, os empreendedores buscam manter seus negócios ativos por seus próprios esforços, uma vez que é a fonte principal de renda, mesmo com a insegurança e instabilidade nos meios de obtenção da madeira.

Esta deficiência no fornecimento de madeira legal torna contraditória a exigência de regularização das atividades, uma vez que não existem incentivos de nenhuma natureza para se obter a madeira da mesma forma, o que também reflete quanto ao posicionamento das empresas no mercado em relação à procedência e a regularização dos produtos.

\section{RESULTADOS E DISCUSÃO}

\section{A regularização dos empreendimentos}

Do total de empreendedores entrevistados, dois deles tem o seu negócio legalizado, mas apenas um de forma completa, sendo regularizado para o funcionamento e para comprar madeira legal, pois tem o CEPROF ativo. Os demais estão em processo de regularização ou tiveram suas licenças vencidas e ainda não procuraram colocar em dia, devido dificuldades financeiras e a complexidade para o cumprimento das exigências burocráticas. 


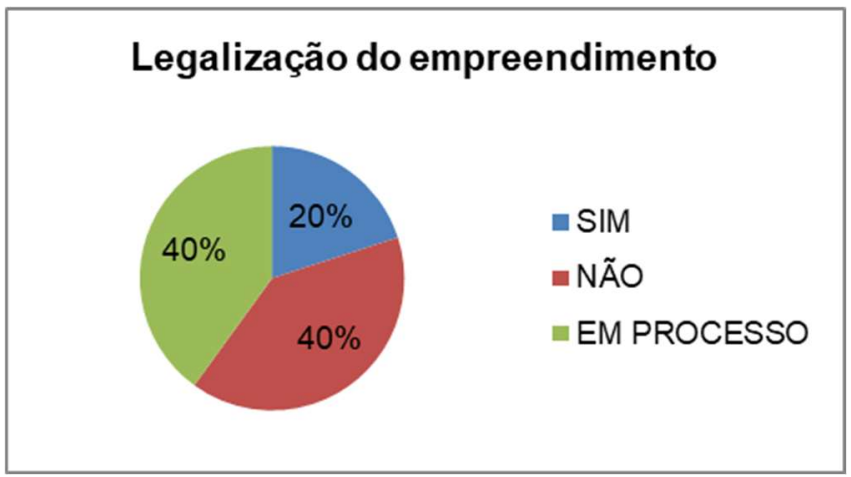

Figura 2: Situação da regularização dos dez empreendimentos amostrados na pesquisa.

A falta de regularização da maioria dos empreendimentos se deve à vários fatores, porém, o maior deles observado foi a falta de orientação em relação as etapas do processo, resultante da falha no papel dos órgãos responsáveis, como a Secretaria Municipal de Meio Ambiente (SEMA), que passou a ser um órgão fiscalizador, e deixou de ser orientador. Além disso, a insegurança dos trabalhadores em relação à obtenção da matéria prima torna desvantajosa a regularização.

A maioria dos pequenos empreendedores opta pela categoria de microempreendedores individuais - MEI, pois este tipo de pessoa jurídica é mais simplificado para seus negócios, porém, da mesma forma devem cumprir com as obrigações legais para desenvolver a atividade. Sendo assim, é importante saber quais os passos do licenciamento ambiental para $\mathrm{MEI}$ de acordo com a legislação que rege no Estado do Pará (Figura 3).

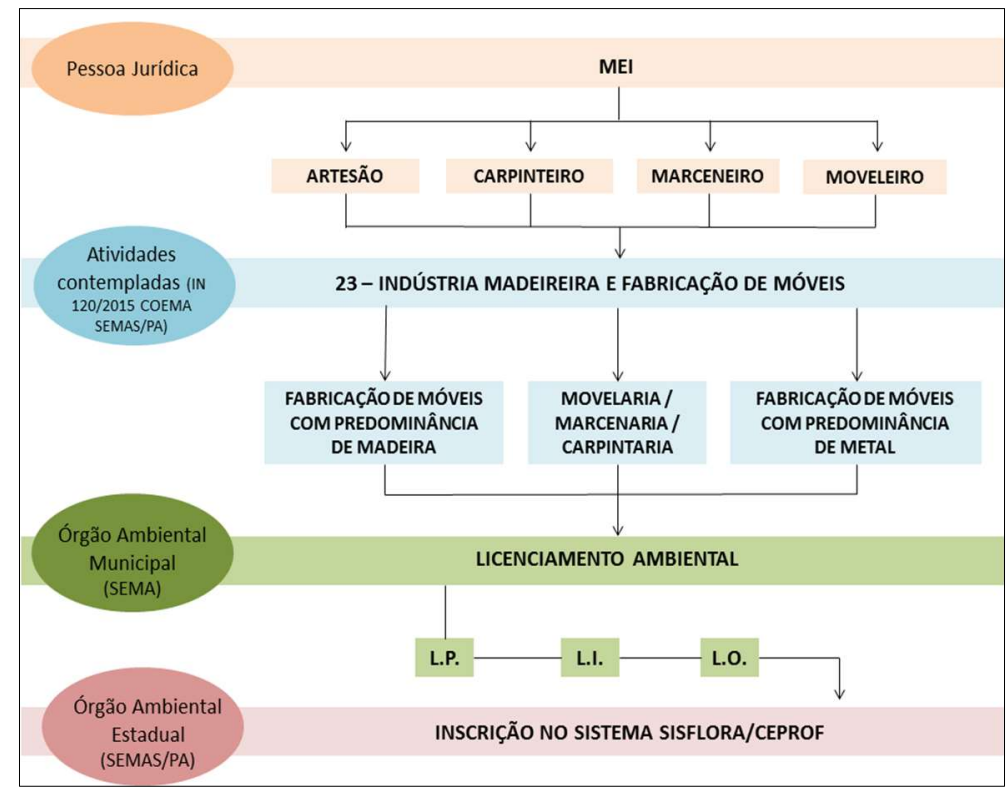

Figura 3: Fluxograma das etapas para a legalização da atividade de um microempreendedor individual - MEI. Fonte: $A$ autora, 2019. Elaborado a partir de informações obtidas junto a SEMAS/PA.

Nota-se que o Manejo Florestal em regime de rendimento sustentável fica fora das atividades contempladas nesse tipo de pessoa jurídica, ficando apto apenas para a etapa de transformação secundária da madeira como a fabricação de móveis, embarcações, entre outras. 


\section{Referências de negócios na cidade}

O Sr M.V.R é proprietário da 'G. Móveis', única movelaria integralmente legalizada no município, que fabrica móveis e esquadrias em geral, comercializados na cidade e região. A empresa existe desde 2002, e apenas em 2019 conseguiu ser legalizada de forma integral, se tornando modelo para as demais movelarias da cidade, por ter conseguido atender todas as exigências legais para a sua regularização. Atualmente, "G. Móveis" conta com 13 funcionários, sendo dois em regime de comissão e o restante por vínculo empregatício em CLT.

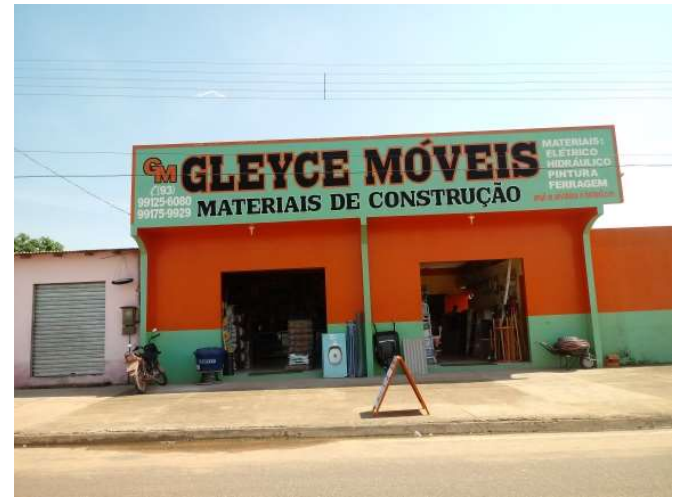

Figura 4: “G. Móveis", única movelaria integralmente legalizada em Óbidos, Pará.

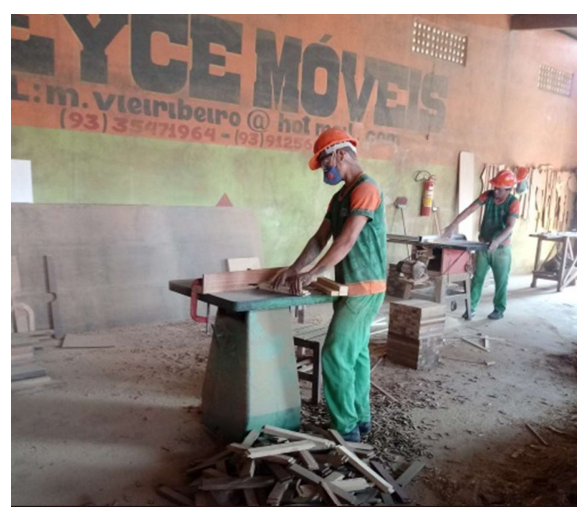

Figura 5: Oficina da movelaria em operação.

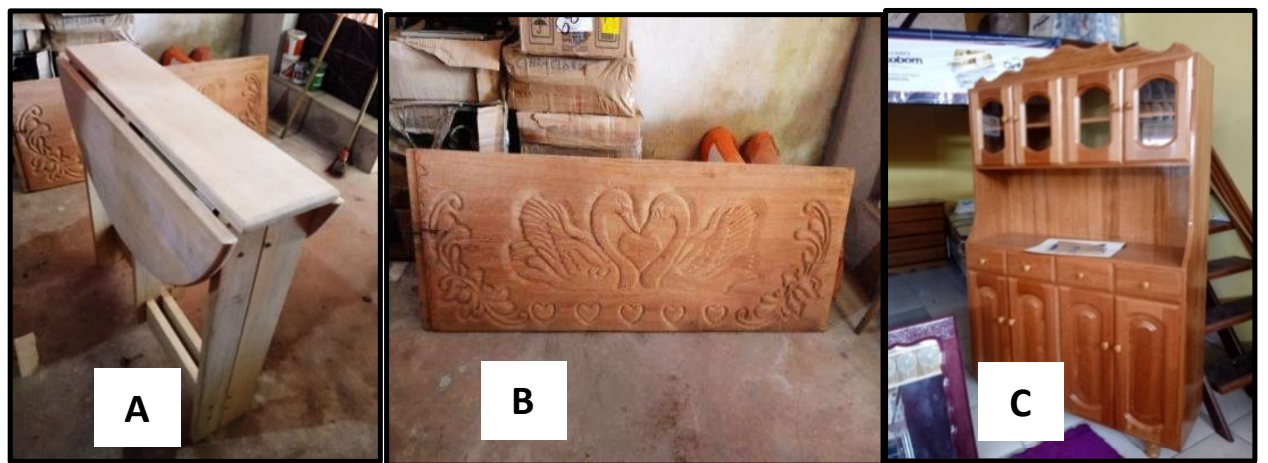

Figura 6: Produtos fabricados e comercializados pela movelaria. A: mesa desmontável; B: cabeceira de cama de casal; C: armário de cozinha.

Porém, mesmo tendo legalidade para o funcionamento do seu negócio, o empreendedor encontra entrave na obtenção da matéria prima, pois apesar do CEPROF ativo, não encontra fornecedor para a compra da madeira legalizada, citando que já comprou uma vez da única serraria legalizada no município, mas que o processo é complexo, pois a produção da serraria não é para atender o mercado consumidor local. Por consequência, ele continua comprando madeira clandestina para atender sua demanda, consumindo em média $150 \mathrm{~m}^{3}$ de madeira serrada por ano.

O proprietário cita que por serem a única movelaria legalizada na cidade, são os únicos que participam de licitação da prefeitura, os demais vêm de Santarém, o que se torna injusto com os moveleiros da própria cidade que poderiam estar atendendo essa demanda, se fossem regularizados. A empresa foi vencedora da última licitação feita pela prefeitura, ficando responsável pela fabricação de carteiras, mesas, armários e quadros para as escolas municipais (Figura 7). 

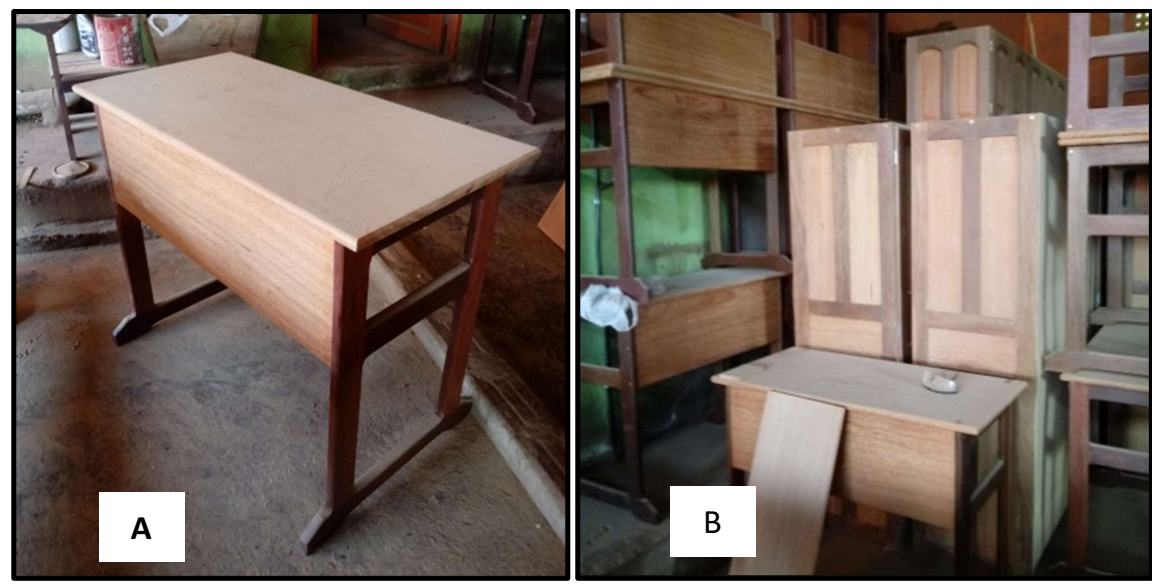

Figura 7: Produtos fornecidos para as escolas municipais firmados em contrato de licitação. A: mesa dos professores. B: armários para escolas.

Outro entrevistado foi o empresário A. G. A. J., 52 anos, proprietário da A. G. Auzier Júnior, a única serraria legalizada do município, fundada em 1994, mas licenciada apenas em 2004, dez anos depois.

A serraria tem contrato com uma empresa de Belém, que paga pelo $\mathrm{m}^{3}$ da madeira serrada que vem de um Plano de Manejo na cidade de Juruti, Pará, distante a aproximadamente $69 \mathrm{Km}$ em linha reta de Óbidos, sendo transportada pelo rio. Toda madeira serrada produzida na empresa vai para a capital do Estado do Pará, ficando em Óbidos apenas os resíduos que são vendidos para fins diversos na cidade.

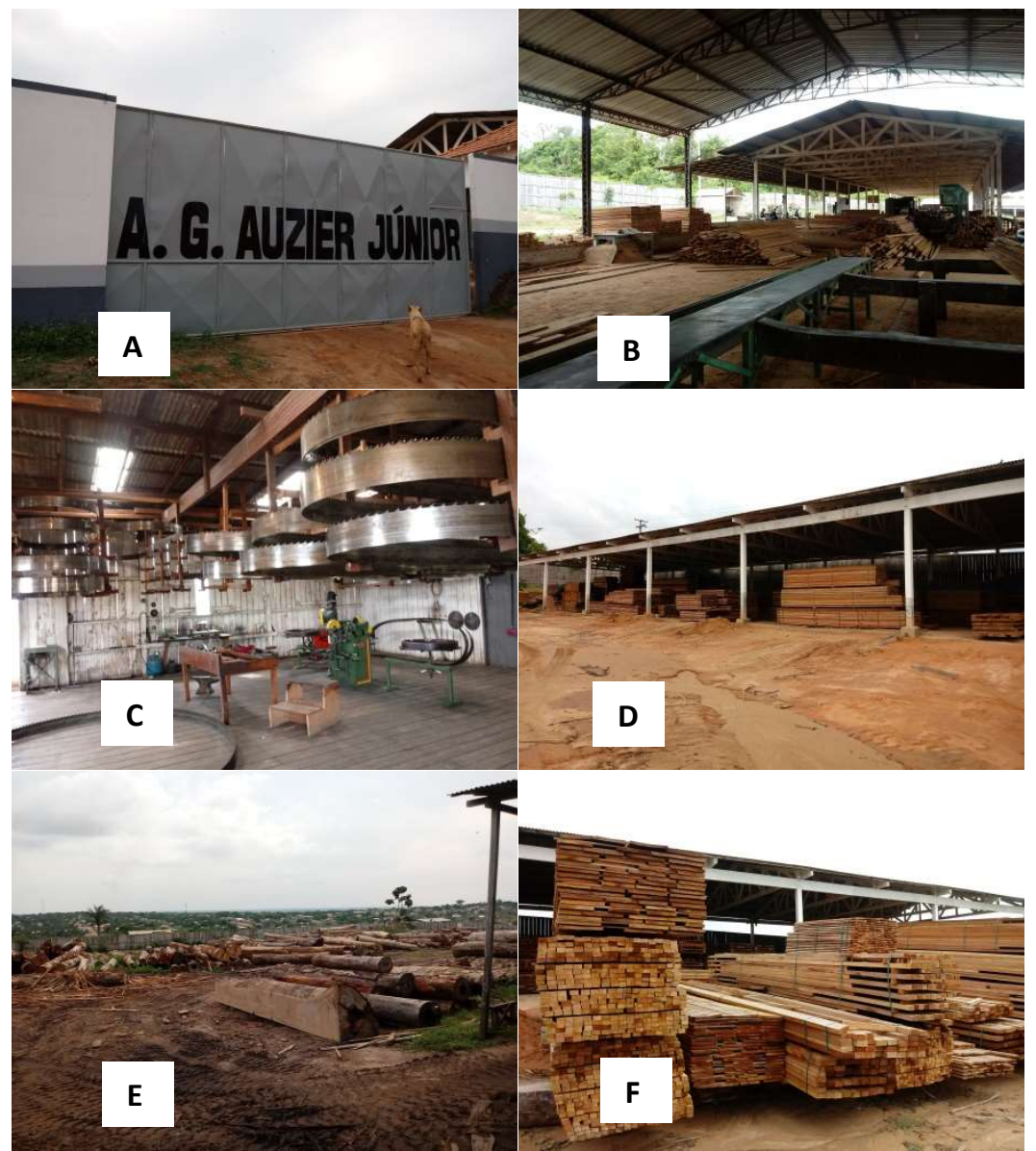

Figura 8: Estrutura da serraria: (A) entrada da serraria, (B) galpão da linha de produção, (C) sala de afiação, (D) pátio de estocagem, $(E)$ galpão de armazenamento e $(F)$ lotes prontos para entrega.

Quando questionado sobre o cenário atual dos empreendimentos que dependem da madeira como 
matéria-prima na cidade, ele se mostrou solícito, dizendo estar disposto a dar apoio para as atividades, e que inclusive já vendeu madeira legal para dois empreendedores informais, porém foi uma exceção, uma vez que eles não possuem os documentos exigidos para se fazer a compra dentro das normas legais.

O relato do empresário abre possibilidades de futuras parcerias para viabilizar o fornecimento de matéria prima para atender a demanda local, dependendo apenas de interesse político para planejamento de estratégias.

\section{Órgãos institucionais}

De acordo com o Secretário Municipal de Meio Ambiente, Sr E. A., as atividades do setor moveleiro/carpintaria tem grande relevância para o município, pois emprega dezenas de famílias, movimenta o comércio local, favorece outra atividade econômica que é o setor pesqueiro, que usa os barcos/bajaras de madeira para a atividade de pesca e deslocamento de ribeirinhos.

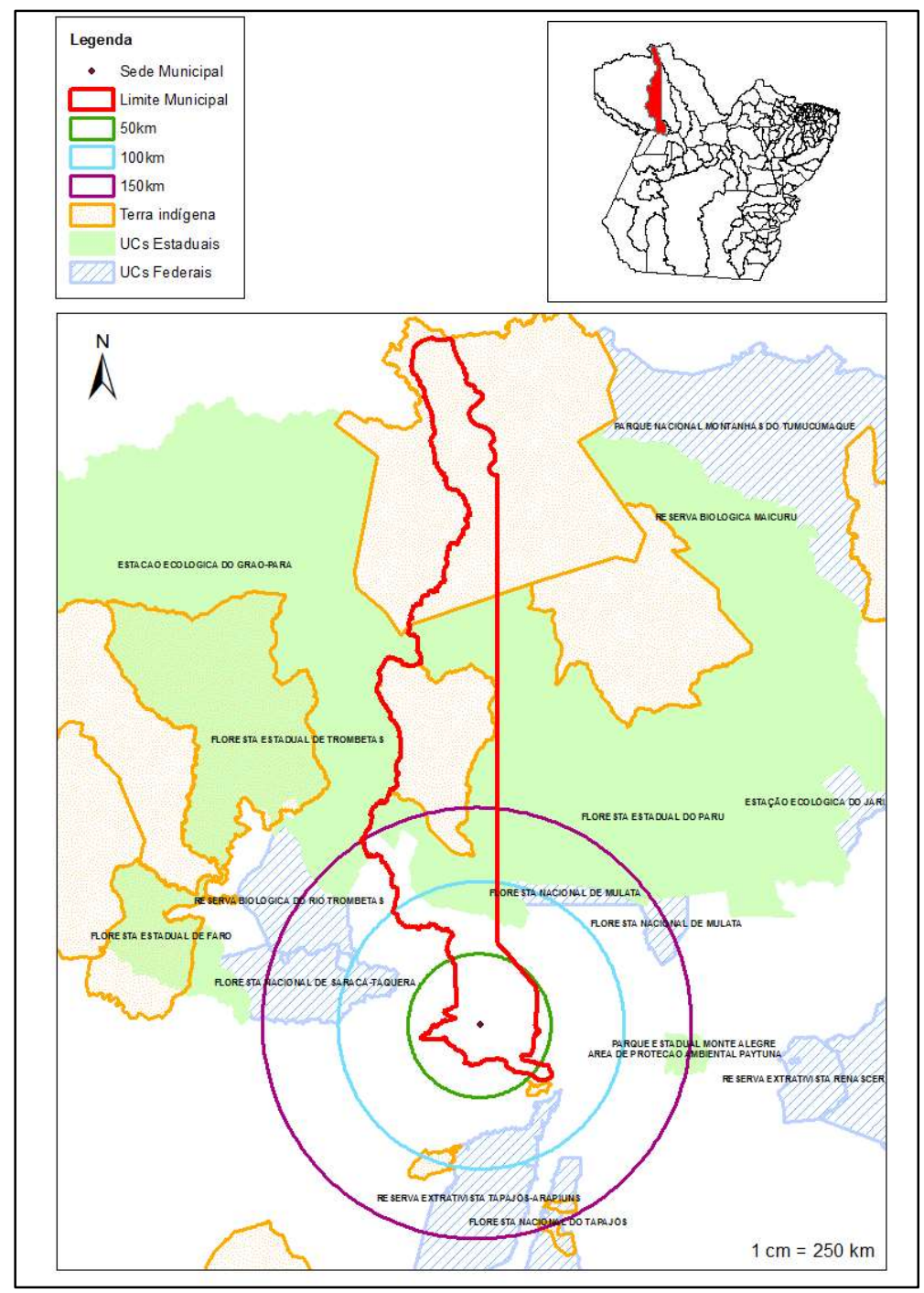

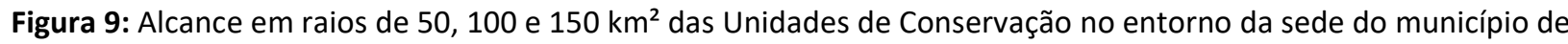
Óbidos.

Em relação às dificuldades que impedem o integral cumprimento do processo de regularização dessas atividades, ele alega falta de quadro adequado de servidores e diz que o principal gargalo da 
deficiência do fornecimento de madeira legal no município é o Código Florestal.

O secretário diz que o papel que a secretaria vem desenvolvendo em relação a essa questão é a administração de conflitos e combate à extração ilegal de madeira, afirmando que também realizam oficinas, palestras, eventos ou profissionalização para o setor na cidade.

Sobre os planos de manejo existentes na cidade, ele afirma que há planos apenas em áreas privadas e que a madeira se destina ao mercado externo, porém, afirma que existem áreas públicas aptas para planos de manejo que tem as espécies utilizadas pelos empreendimentos, um exemplo disso são as áreas de Unidades de Conservação (estadual e federal), mas que, segundo ele, falta interesse do órgão gestor e da própria administração.

Visando contribuir com essa discussão, este trabalho gerou um mapa no entorno de Óbidos em raios de 50, 100 e 150 km² que alcançou diversas Unidades de Conservação (UC) Estaduais e Nacionais, mostrando que existem áreas para prover madeira legal para a cidade.

Na tabela 2, a relação de Unidades de Conservação alcançadas no mapeamento, de uso sustentável, que é o grupo que permite a exploração de madeira, de acordo com o Plano de Gestão da unidade.

Tabela 2: Relação das Unidades de Conservação alcançadas em raios de até 150 km de distância do município de Óbidos.

\begin{tabular}{lll}
\hline INSTÂNCIA RESPONSÁVEL & GRUPO & UNIDADE DE CONSERVAÇÃO \\
\hline \multirow{2}{*}{ ESTADUAL } & USO SUSTENTÁVEL & FLORESTA ESTADUAL DO PARÚ \\
& USO SUSTENTÁVEL & ÁREA DE PROTEÇÃO AMBIENTAL PAYTUNA \\
\hline \multirow{2}{*}{ FEDERAL } & USO SUSTENTÁVEL & FLORESTA NACIONAL DE MULATA \\
& USO SUSTENTÁVEL & FLORESTA NACIONAL DE SARACÁ-TAQUERA \\
& USO SUSTENTÁVEL & RESERVA EXTRATIVISTA TAPAJÓS ARAPIUNS \\
\hline
\end{tabular}

Esse cenário mostra que existe a possibilidade de utilizar áreas protegidas através de práticas sustentáveis e rentáveis dentro de um plano de gestão.

Um exemplo que serve de referência é o manejo de pirarucus na Reserva de Desenvolvimento Sustentável Mamirauá, Amazonas. Com a implantação de técnicas de manejo sustentável para substituir a pesca predatória, a renda obtida pelos pescadores de uma área da reserva com pesca do pirarucu passou de $\mathrm{R} \$ 10,8$ mil em 1999 para $\mathrm{R} \$ 162,5$ mil em 2005. Isso tudo aliado a um aumento de mais de quatro vezes no estoque disponível do peixe (VIANA et al., 2007).

Porém, para isso é preciso que a gestão municipal tenha interesse em promover o diálogo com os órgãos gestores dessas áreas públicas, em busca de atender a demanda das comunidades que anseiam melhorias da qualidade de vida e o desenvolvimento local por meio de práticas legais e reconhecidas por Lei, entretanto, conforme o secretário, a falta de um dispositivo legal a nível municipal específico para essas atividades, dificulta o estabelecimento de políticas públicas como essas.

Por fim, o secretário propõe incentivar os moveleiros/carpinteiros para a legalização, produzir em escala industrial para baratear os custos, buscar comércio do produto em outras praças comerciais, promover capacitação para melhoramento da mão de obra e fazer uso de equipamentos modernos, com baixo custo operacional e alto aproveitamento da madeira utilizada, porém, não apresentou nenhum plano da Secretaria voltado para isso.

A Secretaria Municipal também foi contatada por meio eletrônico, sobre os empreendimentos 
legalizados no município, informando conforme a tabela 3.

Tabela 3: Relação dos empreendimentos licenciados e em processo de licenciamento fornecida pela Secretaria Municipal de Meio Ambiente de Óbidos, em 15 de Outubro de 2019.

\begin{tabular}{lll}
\hline Categoria & Licenciados & Em processo \\
\hline Movelaria & 3 & 3 \\
Tilheiro & 2 & 1 \\
Movelaria - painéis reconstituídos e laminados & 2 & 0 \\
Movelaria, marcenaria, carpintaria & 1 & 0 \\
\hline Total & $\mathbf{8}$ & $\mathbf{4}$ \\
\hline
\end{tabular}

Considerando que dos 10 empreendedores entrevistados apenas 3 estão contemplados nessa relação da SEMA, o que mostra que os outros 7 continuam com dificuldades no acesso aos meios para a busca da legalização.

De acordo com o Engenheiro Florestal P. S., durante a gestão passada e a atual foram realizadas diversas reuniões com os empreendimentos e pessoas que trabalham nesse setor no município, mas boa parte da solução esbarra na questão financeira, e afirma que atualmente o município não dispõe de um instrumento na sua política de meio ambiente capaz de simplificar o processo de licenciamento para empreendimentos que causem baixo impacto ou impacto insignificante.

O profissional diz que atualmente não existem concessões florestais em floresta Pública de Domínio da União, Estado ou do Município, sendo que em Óbidos não foi criado até o momento nenhuma unidade de conservação municipal. Os Planos de Manejo existentes em Óbidos são listados na tabela abaixo, fornecida por P.S., sendo eles localizados em áreas privadas.

Tabela 4: Lista de Planos de Manejo com AUTEF válidas no Município de Óbidos.

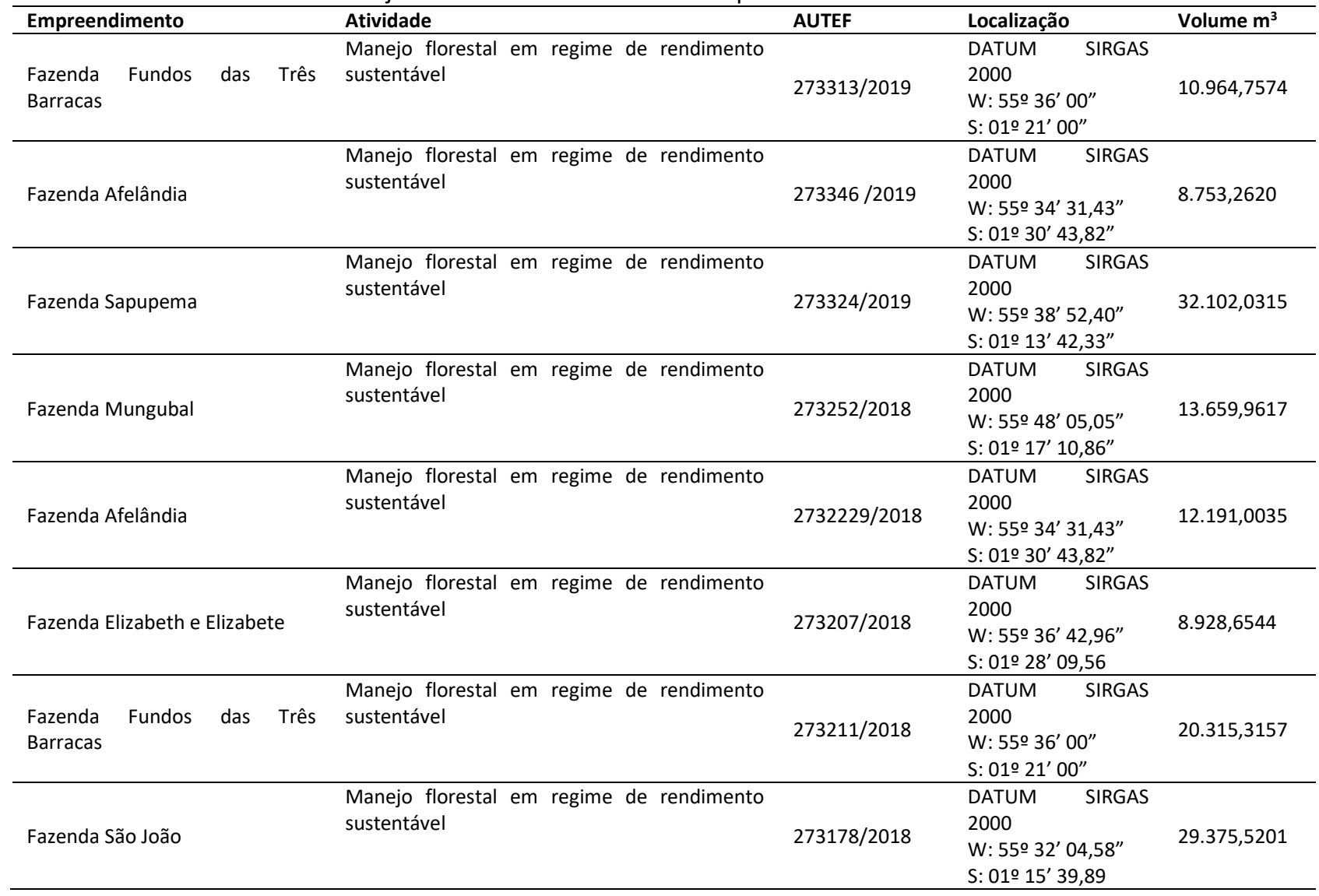


Em relação à ocorrência das espécies nesses planos de manejo existentes, P. S. diz que normalmente é usada Mezilaurus Itauba - Itaúba e Hyemenolobium Petraeum - Angelim nos empreendimentos, e ao analisar as AUTEF com autorização válida, existe a disponibilidade do Angelim, mas não da Itaúba, com isso deverá encontrar um substituto para essa espécie.

Devido a não ocorrência da espécie utilizada na carpintaria naval, foi feito uma relação das espécies utilizadas apenas nas movelarias, afim de estimar a quantidade de madeira disponível para exploração anual autorizadas nos planos de manejo existentes na cidade, relacionando com o total consumido pelas movelarias, conforme tabela 5 .

Tabela 5: Relação das espécies de interesse comercial das movelarias ocorrentes nos planos de manejo com Autorização de Exploração válida em Óbidos, Pará.

\begin{tabular}{|c|c|c|c|c|c|c|c|c|c|c|}
\hline \multirow{2}{*}{$\begin{array}{l}\text { ESPÉCIES DE INTERESSE } \\
\text { COMERCIAL }\end{array}$} & \multicolumn{8}{|c|}{ QUANTIDADE DE TORA AUTORIZADA NO POA (M³) } & \multicolumn{2}{|c|}{ TOTAL POR ESPÉCIE $\left(\mathrm{M}^{3}\right)$} \\
\hline & PMF 1 & PMF 2 & PMF 3 & PMF 4 & PMF 5 & PMF 6 & PMF 7 & PMF 8 & TORA & MADEIRA SERRADA \\
\hline ANGELIM & 350,69 & 296,34 & 1592,59 & 9321,78 & 765,20 & 362,20 & 673,13 & 664,45 & 14026,38 & 7013,19 \\
\hline CEDRO & 45,32 & 28,50 & 0,00 & 178,48 & 244,48 & 47,06 & 118,39 & 0,00 & 662,23 & 331,11 \\
\hline CUMARU & 2182,29 & 255,24 & 5555,60 & 1124,54 & 279,45 & 192,85 & 3295,58 & 1796,00 & 14681,54 & 7340,77 \\
\hline IPÊ & 67,64 & 1799,98 & 447,94 & 389,66 & 3168,05 & 1666,30 & 61,48 & 744,30 & 8345,34 & 4172,67 \\
\hline MAÇARANDUBA & 1618,28 & 0,00 & 10119,77 & 3287,42 & 0,00 & 4,83 & 3352,08 & 10866,35 & 29248,73 & 14624,37 \\
\hline MARUPÁ & 369,37 & 0,00 & 1142,48 & 0,00 & 251,11 & 355,45 & 235,20 & 536,85 & 2890,46 & 1445,23 \\
\hline MUIRACATIARA & 34,01 & 57,43 & 178,45 & 0,00 & 40,01 & 0,00 & 6,76 & 50,25 & 366,90 & 183,45 \\
\hline \multicolumn{9}{|c|}{ TOTAL A SER EXPLORADO EM 1 ANO } & 70221,59 & 35110,79 \\
\hline \multicolumn{9}{|c|}{ TOTAL CONSUMIDO PELAS MOVELARIAS ANUALMENTE } & 84 & 42 \\
\hline
\end{tabular}

\section{CONCLUSÕES}

A aplicação dos questionários semiestruturados revelou que existe entre os entrevistados um sentimento comum de angústia e impotência diante das dificuldades, demostrando descrédito no papel do órgão ambiental, o que cria uma barreira que impede a participação efetiva dos atores envolvidos para debater a importância dos assuntos pertinentes ao setor.

A burocratização se mostrou como o grande entrave, sendo citada com unanimidade pelos entrevistados, revelando um cenário complexo e carente de apoio técnico, jurídico e governamental, onde a falha dos órgãos competentes reflete nitidamente os gargalos da cadeia produtiva da madeira.

O estudo apontou que no formato que se encontra atualmente a utilização dos Planos de Manejo para prover madeira para fora do município, estão sendo excluídas as chances de potencializar a economia local, além de incentivar a ilegalidade, pois os trabalhadores da área continuam se arriscando e retirando madeira ilegalmente na tentativa de manter seus negócios ativos.

Sobre uso das Unidades de Conservação (estadual e federal) da região para prover madeira ao município, constatou-se que há falta de iniciativa do poder público municipal em liderar essa demanda, porém, atrelado a isso, tem a concorrência injusta de pequenos e médios empresários com as grandes empresas nacionais e internacionais na disputa pelo contrato da concessão florestal das áreas.

Há a necessidade de criar um instrumento jurídico, como uma cooperativa, afim de unir e organizar a classe, para criar mecanismos que venham valorizar seus produtos, promover captação de recursos e viabilizar projetos para prover madeira para os cooperados. 
Por fim, a consolidação de políticas públicas implica na atualização dos instrumentos legais municipal, pois a cidade de Óbidos, assim como toda a região, tem suas especificidades e realidades que precisam ser consideradas e respeitadas, sendo fundamentais para o estabelecimento de políticas públicas que se enquadrem e atendam os anseios locais, tornando as atividades do setor florestal um grande potencial econômico para o desenvolvimento do município e região.

\section{REFERÊNCIAS}

BRAGA, E.; SARROUF, L.. Aquisição responsável de madeira na construção civil: Guia Prático para as Construtoras. São Paulo: WWF, 2011.

BRASIL. Lei n. 12.527, de 18 de novembro de 2011. Lei de acesso à informação. 190 da Independência e 123ㅇ da República. Brasília: DOU, 2011.

BRASIL. Resolução CONAMA n. 237, de 19 de dezembro de 1997. Dispõe sobre a revisão e complementação dos procedimentos e critérios utilizados para o licenciamento ambiental. Brasília: DOU, 1997.

CASSILHA, A. C.; PODLASEK, C. L.; JUNIOR, E. F. C.; SILVA, M. C.; MENGATTO, S. N. F.. Indústria moveleira e resíduos sólidos: considerações para o equilíbrio ambiental. Revista Educação \& Tecnologia, n.8, 2003.

COIMBRA, J.. Linguagem e percepção ambiental. In: PHILIPPI JUNIOR, A.; ROMÉRO, M.; BRUNA, C.. Curso de gestão ambiental. Barueri: Manole, 2004. p.525-570.

MAY, P. H.; MILLIKAN, B.; AMARAL, C.; ASCHER, P.. Instrumentos econômicos para o desenvolvimento sustentável na Amazônia brasileira. Brasília: Ministério do Meio Ambiente, 2005.

MILLER, F.. Seja legal: boas práticas para manter a madeira ilegal fora de seus negócios. 2006.

MOREIRA, J.. Importância do setor florestal brasileiro com ênfase nas plantações florestais comerciais. In.: OLIVEIRA, Y. M. M.; OLIVEIRA, E. B.. Plantações florestais: geração de benefícios com baixo impacto ambiental. Brasília: Embrapa, 2017. p.14-112.

PATTON, M. Q.. Qualitative research and evalution methods. 3 ed. Washington: Sage Publications, 2001.
PEREIRA, D.; SANTOS, D.; VEDOVETO, M.; GUIMARÃES, J.; VERÍSSIMO, A.. Fatos florestais da Amazônia 2010. Belém: Imazon, 2010.

QUINTAS, J.. Introdução à gestão ambiental pública. 2 ed. Brasília: IBAMA, 2006.

RODRIGUES, A. F.. Manejo Florestal Comunitário na Floresta Nacional do Tapajós. Belém: COOMFLONA, 2019.

SOUSA, R. G.. Avaliação do modelo de monitoramento ambiental no Estado do Pará: estudo de caso da SEMA/PA. Dissertação (Mestrado) - Universidade Federal do Pará, Belém, 2013.

TEIXEIRA, C. O.. Desenvolvimento sustentável em Unidade de Conservação: a "naturalização" do social. Rev. Brasileira de Ciências Sociais, v.20, n.59, 2005.

VIANA, J. P.; CASTELLO, L.; DAMASCENO, J. M. B.; AMARAL, E. S. R.; ESTUPIÑÁN, G. M. B.; ARANTES, C.; BATISTA, G. S.; GARCEZ, D. S.; BARBOSA, S.. Manejo comunitário do pirarucu Arapaima gigas na Reserva de Desenvolvimento Sustentável Mamirauá - Amazonas, Brasil. In: PRATES, A. P.; BLANC, D.. Áreas aquáticas protegidas como instrumento de gestão pesqueira. Brasília: Ministério do Meio Ambiente, 2007.

WHA. World Health Association. Division of Mental Health. Qualitative Research for Health Programmes. Geneva: WHA, 1994.

ZENID, J. G.. Identificação e agrupamento das madeiras serradas empregadas na construção civil habitacional na cidade de São Paulo. Tese (Mestrado) - Escola Superior de Agricultura Luiz de Queiroz da Universidade de São Paulo, Piracicaba, 1997.

A CBPC - Companhia Brasileira de Produção Científica (CNPJ: 11.221.422/0001-03) detém os direitos materiais desta publicação. Os direitos referem-se à publicação do trabalho em qualquer parte do mundo, incluindo os direitos às renovações, expansões e disseminações da contribuição, bem como outros direitos subsidiários. Todos os trabalhos publicados eletronicamente poderão posteriormente ser publicados em coletâneas impressas sob coordenação da Sustenere Publishing, da Companhia Brasileira de Produção Científica e seus parceiros autorizados. Os (as) autores (as) preservam os direitos autorais, mas não têm permissão para a publicação da contribuição em outro meio, impresso ou digital, em português ou em tradução. 